\title{
Role of Pap smear in the screening of cervical cancer: A hospital based study
}

\author{
Niraj Nepal ${ }^{1}$, Prabesh Kumar Choudhary ${ }^{1}$, Sagar Paudel ${ }^{2}$, Utsav Nath \\ Adhikari $^{2}$
}

${ }^{\prime}$ Department of Pathology, Nobel Medical College and Teaching Hospital, Biratnagar, Nepal.

${ }^{2}$ Nobel Medical College and Teaching Hospital, Biratnagar, Nepal.

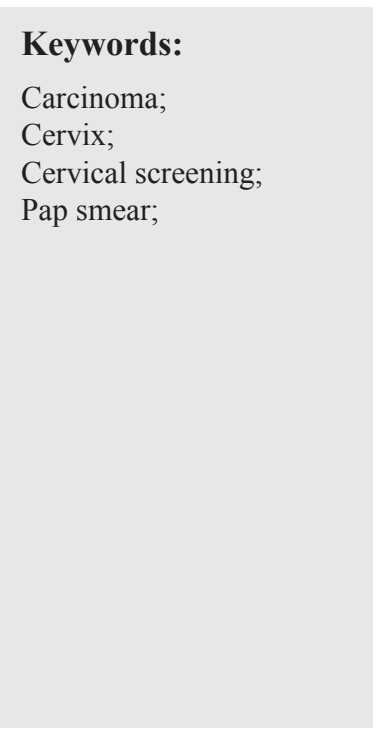

\begin{abstract}
Background: Incidence of cervical cancer has decreased in the developed world due to use of Pap smear as a screening tool. It has been proven as a sensitive screening tool for cervical cancer but its coverage is very low in Nepal. The objective of this study is to find out the incidence of cervical epithelial cell abnormality, its demographic distribution and common presenting symptoms.

Materials and Methods: This retrospective comparative study was conducted in Nobel Medical College and Teaching Hospital, Biratnagar, Nepal. A total of 950 patients attending gynecological department with various symptoms were enrolled. Only 902 patients were included in the study after excluding inadequate samples.

Results: The mean age of patient was $37.94 \pm 12.74$ years with minimum age of 18 and maximum age of 79 years. The mean age of patients with epithelial abnormality was $47.88 \pm 8.87$ years. The highest number of Atypical squamous cells of undetermined significance was observed between 51-60 years $(1.1 \%)$ whereas Low and High grade squamous intraepithelial lesion were mostly observed between $41-50$ years $(3.2 \%$ and $0.4 \%$ respectively). The most common symptom was vaginal discharge $(41.6 \%)$ followed by pain abdomen $(23.1 \%)$.
\end{abstract}

Conclusion: Pap smear is a cost effective, sensitive and simple screening test for cervical premalignant and malignant lesions.

\section{Correspondence: \\ Dr. Niraj Nepal, MD \\ Assistant Professor, Department of Pathology, \\ Nobel Medical College and Teaching Hospital, Biratnagar, Nepal. \\ ORCID ID: 0000-0001-5863-5445 \\ Email: nepalniraj@gmail.com \\ Received : July $16^{\text {th }} 2019$; Accepted : August $26^{\text {th }} 2019$}

Citation: Nepal N, Choudhary PK, Paudel S, Adhikari UN. Role of Pap smear in the screening of cervical cancer: A hospital based study. J Pathol Nep. 2019;9:1530-4. DOI 10.3126/jpn.v9i2.24876

Copyright: This is an open-access article distributed under the terms of the Creative Commons Attribution 4.0 International License, which permits unrestricted use, distribution, and reproduction in any medium, provided the original author and source are credited.

\section{INTRODUCTION}

Cervical cancer is the fourth most common cancer amongst women worldwide and second to breast cancer in developing countries and was responsible for 569,847 new cases and 311,365 deaths in 2018 worldwide. ${ }^{1}$ According to data of National Cancer Registry Programme (NCRP), cervical cancer is the most common malignancy among women in Nepal. $^{2}$

Over $80 \%$ of cervical cancers are detected in sub-Saharan Africa in late stages; due to lack of knowledge about the disease and lack of screening services., ${ }^{3,4}$ Women with cervical cancer are not identified until they are at advanced 
stages of disease which can be correlated with low survival rates. ${ }^{5}$

Cervical cancer can be detected by using several screening techniques. Cervical Pap smear is a sensitive test for early screening of cervical lesions and is the most widely used system. ${ }^{6}$ It is stated that the annual incidence and prevalence of cervical cancer has decreased by $50-70 \%$ after the introduction of population-based screening. ${ }^{7}$ So, if women undergo screening for cervical cancer, it can be detected in early stages thereby reducing the mortality and morbidity. Several studies have stated that the available services provided have not been properly utilized in different countries like Uganda. A recent study conducted found that only $7 \%$ of the women had undergone screening for cervical cancer and $4.8 \%$ had undergone screening in Eastern Uganda. ${ }^{8,9}$

The National guideline for cervical cancer screening and prevention in Nepal 2010 has 'Visual Inspection of cervix with Acetic Acid' as the screening tool instead of pap smear test. ${ }^{2}$ Women of Nepal are getting pap smear test from different health institutes after counseling from health workers. There has been limited studies conducted regarding pap smear test in Nepalese women and its influence in reducing burden of cervical carcinoma in Nepal.

\section{MATERIAL AND METHODS}

This retrospective and comparative study was conducted on patients, presenting with various gynecological symptoms that attended the outpatient department of Gynecology, Nobel medical college and teaching hospital, Biratnagar, Nepal and underwent pap smear test. The study was conducetd for period of one and half year from September 2017 to February 2019. Ethical clearance was obtained from Institutional ethics committee of Nobel Medical College and teaching hospital. Patients with inadequate samples and cervical growth were excluded from the study.

A total of 950 patients had attended gynecological department with various symptoms and were enrolled in our study. Only 902 patients were studied after excluding inadequate samples. The age, parity, age of marriage, age of first childbirth, residency and religion of these patients were recorded in a proforma for demographic comparison. The pap smear was reported according to Bethesda System of Reporting Cervical Cytology 2014.

The findings were categorized as: 1) Negative for malignancy 2) Inflammatory changes 3) Atypical squamous cells of undetermined significance (ASCUS) 4) Low grade squamous intraepithelial lesion (LSIL) and 5) High grade squamous intraepithelial lesion (HSIL).

The results of the study were statistically analyzed using SPSS version 25 , using mean \pm standard deviation, percentage, frequency and comparative study was done using chi-square test. A p-value of $<0.05$ was considered statistically significant.

\section{RESULTS}

A total of 902 patients were studied after excluding those with inadequate sample. The mean age of the patients was $37.94 \pm 12.74$ years with minimum age of 18 years and maximum age of 79 years. The highest number of ASCUS was observed in women between 51-60 years $(1.1 \%)$ whereas LSIL and HSIL were mostly observed in women between $41-50$ years ( $3.2 \%$ and $0.4 \%$ respectively). Epithelial cell abnormity was found in $8.4 \%$ of screened women and in patients with epithelial cell abnormality, $17.11 \%$ of patients with parity two or less and $82.89 \%$ with parity more than two. Similarly, ASCUS, LSIL and HSIL

Table 1: Demographic profile of patients and its correlation with pap smear finding

\begin{tabular}{|c|c|c|c|c|c|c|}
\hline & $\begin{array}{c}\begin{array}{c}\text { Negative for } \\
\text { malignancy } \\
(n=472,52.3 \%)\end{array} \\
\end{array}$ & $\begin{array}{c}\text { Inflammation } \\
(\mathrm{n}=354,39.2 \%)\end{array}$ & $\begin{array}{c}\text { ASCUS } \\
(n=21,2.3 \%)\end{array}$ & $\begin{array}{c}\text { LSIL } \\
(\mathrm{n}=\mathbf{4 8 , 5 . 3 \% )}\end{array}$ & $\begin{array}{c}\text { HSIL } \\
(\mathrm{n}=\mathbf{7}, \mathbf{0 . 8} \%)\end{array}$ & $\begin{array}{c}\text { TOTAL } \\
(\mathrm{n}=\mathbf{9 0 2}, \mathbf{1 0 0} \%)\end{array}$ \\
\hline \multicolumn{7}{|c|}{ AGE (Years) } \\
\hline $18-30$ & $149(16.5 \%)$ & $143(15.9 \%)$ & $0(0 \%)$ & $2(0.2)$ & $0(0 \%)$ & $294(32.6 \%)$ \\
\hline $31-40$ & $162(18.0 \%)$ & $109(12.1 \%)$ & $2(0.2 \%)$ & $7(0.8 \%)$ & $2(0.2 \%)$ & $282(31.3 \%)$ \\
\hline $41-50$ & $93(10.3 \%)$ & $53(5.9 \%)$ & $5(0.6 \%)$ & $29(3.2 \%)$ & $4(0.4 \%)$ & $184(20.4 \%)$ \\
\hline $51-60$ & $40(4.4 \%)$ & $28(3.1 \%)$ & $10(1.1 \%)$ & $8(0.9 \%)$ & $1(0.1 \%)$ & $87(19.6 \%)$ \\
\hline $61-70$ & $26(2.9 \%)$ & $11(1.2 \%)$ & $4(0.4 \%)$ & $2(0.2 \%)$ & $0(0 \%)$ & $43(4.8 \%)$ \\
\hline$>70$ & $2(0.2)$ & $10(1.1 \%)$ & $0(0 \%)$ & $0(0 \%)$ & $0(0 \%)$ & $12(1.3 \%)$ \\
\hline \multicolumn{7}{|c|}{ PARITY } \\
\hline P1 & $140(15.5 \%)$ & $107(11.9 \%)$ & $0(0 \%)$ & $0(0 \%)$ & $0(0 \%)$ & $247(27.4 \%)$ \\
\hline P2 & $117(13.0 \%)$ & $137(15.2 \%)$ & $3(0.3 \%)$ & $9(1 \%)$ & $1(0.1 \%)$ & $267(29.6 \%)$ \\
\hline P3 & $126(14 \%)$ & $64(7.1 \%)$ & $7(0.8 \%)$ & $14(1.6 \%)$ & $2(0.2 \%)$ & $213(23.6 \%)$ \\
\hline$>\mathrm{P3}$ & $89(9.9 \%)$ & $46(5.1 \%)$ & $11(1.2 \%)$ & $25(2.8 \%)$ & $4(0.4 \%)$ & $175(19.4 \%)$ \\
\hline
\end{tabular}


Table 2: Correlation of pap smear findings with signs and symptoms

\begin{tabular}{|c|c|c|c|c|c|c|}
\hline Symptoms & $\begin{array}{c}\text { Negative for } \\
\text { malignancy } \\
(n=472,52.3 \%)\end{array}$ & $\begin{array}{l}\text { Inflammation } \\
(\mathrm{n}=354,39.2 \%)\end{array}$ & $\begin{array}{c}\text { ASCUS } \\
(n=21,2.3 \%)\end{array}$ & $\begin{array}{c}\text { LSIL } \\
(\mathrm{n}=48,5.3 \%)\end{array}$ & $\begin{array}{c}\text { HSIL } \\
(\mathrm{n}=\mathbf{7}, \mathbf{0 . 8} \%)\end{array}$ & $\begin{array}{c}\text { TOTAL } \\
(\mathrm{n}=\mathbf{9 0 2}, \mathbf{1 0 0} \%)\end{array}$ \\
\hline Asymptomatic & $55(6.1 \%)$ & $43(4.8 \%)$ & $2(0.2 \%)$ & $6(0.7 \%)$ & $2(0.2 \%)$ & $108(12 \%)$ \\
\hline Pain abdomen & $107(11.9 \%)$ & $84(9.3 \%)$ & $5(0.6 \%)$ & $11(1.2 \%)$ & $1(0.1 \%)$ & $208(23.1 \%)$ \\
\hline Vaginal discharge & $209(23.2 \%)$ & $146(16.2 \%)$ & $4(0.4 \%)$ & $16(1.8 \%)$ & $0(0 \%)$ & $375(41.6 \%)$ \\
\hline $\begin{array}{l}\text { Irregular menstrual } \\
\text { bleeding }\end{array}$ & $46(5.1 \%)$ & $33(3.7 \%)$ & $3(0.3 \%)$ & $5(0.6 \%)$ & $2(0.2 \%)$ & $89(9.9 \%)$ \\
\hline $\begin{array}{l}\text { Post-menopausal } \\
\text { bleeding }\end{array}$ & $9(1 \%)$ & $25(2.8 \%)$ & $3(0.3 \%)$ & $4(0.4 \%)$ & $0(0 \%)$ & $41(4.5 \%)$ \\
\hline Post-coital bleeding & $23(2.5 \%)$ & $11(1.2 \%)$ & $0(0 \%)$ & $2(0.2 \%)$ & $2(0.2 \%)$ & $38(4.2 \%)$ \\
\hline Urinary Frequency & $15(1.7 \%)$ & $9(1 \%)$ & $2(0.2 \%)$ & $3(0.3 \%)$ & $0(0 \%)$ & $29(3.2 \%)$ \\
\hline $\begin{array}{l}\text { Something coming } \\
\text { out of vagina }\end{array}$ & $8(0.9 \%)$ & $3(0.3 \%)$ & $2(0.2 \%)$ & $1(0.1 \%)$ & $0(0 \%)$ & $14(1.6 \%)$ \\
\hline
\end{tabular}

Table 3: Comparison of parity with pap smear finding using chi-square test

\begin{tabular}{|c|c|c|c|}
\hline Parity & Pap Sn & ndings & P Value \\
\hline & Negative and inflammatory & ASCUS, LSIL and HSIL & \\
\hline$\leq \mathbf{P 2}$ & $501(97.5 \%)$ & $13(2.5 \%)$ & $<0.001^{*}$ \\
\hline$>\mathrm{P2}$ & $325(83.8 \%)$ & $63(16.2 \%)$ & \\
\hline
\end{tabular}

*statistically significant

were mostly found in women having more than 3 children $(1.2 \%, 2.8 \%$ and $0.4 \%$ respectively) (Table 1$)$.

The women enrolled in the study were mostly Hindu (79.8\%) and urban residents (76.3\%). The most common symptom was vaginal discharge $(41.6 \%)$ followed by pain abdomen (23.1\%), irregular menstrual bleeding $(9.9 \%)$, post-menopausal bleeding $(4.5 \%)$, post-coital bleeding $(4.2 \%)$, urinary frequency $(3.2 \%)$ and something coming out of vagina (1.6\%). A total of 108 cases $(12 \%)$ were asymptomatic (Table 2). The incidence of LSIL was higher in patients complaining of vaginal discharge $(1.8 \%)$ whereas HSIL was found in patient complaining of irregular menstrual bleeding, post coital bleeding and in asymptomatic cases. The pap smear was negative for $52.3 \%$ of patients whereas $39.2 \%$ of patient showed inflammatory changes. The mean age of epithelial abnormality in our study was $47.88 \pm 8.87$ years.

In our the study group, age of first childbirth was highest in age group above 20 years (90.1\%). In the study, Cervical epithelial cell abnormality was found in $5.6 \%$ of patients with age at marriage age $\leq 18$ years as compared to $9.3 \%$ of patients with age at marriage age $>18$ years and this , which doesn't show any statistically significance difference ( $p$-value $=0.058)$. However, women having more than two children showed statistically significant epithelial cell abnormality as compared to women having two or less children ( $\mathrm{p}$-value $\leq<0.001$ ) as shown in Table 3 .

\section{DISCUSSION}

The incidence of cervical carcinoma and pap smear coverage is not adequately studied in Nepal. There is no data available at national level regarding pap smear coverage as it is not the recommended screening test for cervical cancer prevention in the "National cervical cancer prevention policy of Nepal". ${ }^{2}$

Out of 902 patients, the incidence of ASCUS was found to be $2.3 \%$, LSIL $5.3 \%$ and HSIL $0.8 \%$ percent. Populationbased study done in Bharatpur, Nepal by Sherpa AT et. al. found ASCUS in $2.8 \%$, LSIL in $0.2 \%$ and HSIL in $0.5 \%$ patients which is lower as compared to our hospital based study..$^{10}$ Similar hospital-based study done in Uttar Pradesh, India showed ASCUS in $2.9 \%$, LSIL in 5.09\% and HSIL in $0.48 \%$ of screened women. ${ }^{11}$ In our study, epithelial cell abnormality was found to be $8.4 \%$ which is comparable to studies done by Sachan PL et al. (8.48\%) and Al Eyd et al. $(9.05 \%) .{ }^{11,12}$

Proportion of patients with ASCUS was highest (1.1\%) in 51-60 years age group, LSIL (3.2\%) in 41-50 years and HSIL $(0.4 \%)$ in $41-50$ years age group. A study done in Bharatpur showed ASCUS/LSIL highest (3.8\%) in agegroup 15-29 and HSIL highest in 30-55 years. ${ }^{10}$

In our study, inflammatory changes were seen in $39.2 \%$ of the patients. Few studies have reported that the chance 
of development of cervical intraepithelial lesions is higher in women who have persistent inflammation. ${ }^{13}$ Pap smear should be repeated after antibiotic treatment.

In our study, epithelial cell abnormality was found in $17.11 \%$ of patients with parity two or less and $82.89 \%$ with parity more than two as compared to study done in Bangladesh by Banik $U$ et al. which showed $17.27 \%$ and $82.73 \%$ respectively. ${ }^{14}$

The most common symptom was vaginal discharge $(23.2 \%)$ followed by pain abdomen (11.9\%) and irregular menstrual bleeding $(5.1 \%)$. This is in concordance to a study done in Uttar Pradesh, India which showed vaginal discharge in $39.96 \%$, pain abdomen in $26.63 \%$ and irregular menstrual bleeding in 12.78 percent. ${ }^{11}$

The incidence of ASCUS was higher $(0.6 \%)$ in patients complaining of pain abdomen whereas LSIL was higher $(1.8 \%)$ in patients with vaginal discharge and HSIL in patients with irregular bleeding $(0.2 \%)$ and post-coital bleeding $(0.2 \%)$ comparable to other study. ${ }^{11}$

In context of Nepal, pap smear screening test is usually done in symptomatic patients by gynecologist as part of investigation. Therefore, screening facilities should be extended to primary health center level to increase the coverage of cervical screening and early diagnosis of premalignant and malignant lesion in asymptomatic patients.

\section{CONCLUSIONS}

Pap smear testing is noninvasive, sensitive and simple screening test for cervical premalignant and malignant lesions. The burden of cervical carcinoma can be reduced by screening patients visiting gynecological department and by inclusion of pap smear testing in national programme.

\section{Recommendations}

We recommend sexually active female to undergo routine pap smear testing to reduce the mortality and morbidity related to cervical carcinoma. We recommend Nepal government to launch cancer screening programme and spread the health education regarding benefit of screening tests.

\section{Limitation of Study}

The study could have been better if all the risk factors of cervical carcinoma were retrospectively studied in relation to the outcome of pap smear testing.

\section{Acknowledgement}

We are very grateful to the Department of Gynecology,
Nobel Medical College for granting permission to evaluate and perform research on patients with gynecological symptoms.

\section{Conflict of interest: None}

\section{REFERENCES}

1. Bray F, Ferlay J, Soerjomataram I, Siegel RL, Torre LA, Jemal A. Global cancer statistics 2018: GLOBOCAN estimates of incidence and mortality worldwide for 36 cancers in 185 countries. CA Cancer J Clin 2018;68(6):394-424. Crossref

2. Family Health Division (FHD). National Guideline forCervical Cancer Screening and Prevention in Nepal; 2011. (Cited on 18th June 2019). Crossref

3. Bingham A, Bishop A, Coffey P, Winkler J, Bradley J, Dzuba I, Agurto I.Factors affecting utilization of cervical cancer prevention services in low resource settings. Salud Publica Mex. 2003;45 Suppl 3:S408-16. Crossref

4. Cristina Herdman JS. Planning appropriate cervical cancer prevention programs. In: Seattle Program for Appropriate Technology in Health (PATH). 2nd ed. 2000. screening.iarc.fr $>$ doc $>$ cxca-planning-approprog-guide

5. Mutyaba T, Faxelid E, Mirembe F, Weiderpass E. Influences on uptake of reproductive health services in Nsangi community of Uganda and their implications for cervical cancer screening. Reprod Health. 2007;4:4. Crossref

6. Solomon D1, Davey D, Kurman R, et al. The 2001 Bethesda System; Terminology for reporting results of cervical cytology. JAMA. 2002 Apr 24;287(16):2114-9. $\underline{\text { Crossref }}$

7. Guidelines for cervical cancer screening. Government of India and WHO Collaborative Programme. screening.iarc.fr > doc > WHO_ India_CCSP_guidelines_2005. (Cited on 17th June 2019). Crossref

8. Twinomujuni C, Nuwaha F, Babirye JN. Understanding the Low level of cervical cancer screening in Masaka Uganda using the ASE model: a community-based survey. PLoS One. 2015;10:e0128498. $\underline{\text { Crossref }}$

9. Ndejjo R, Mukama T, Musabyimana A, Musoke D. Uptake of cervical cancer screening and associated factors among women in Rural Uganda: a cross sectional study. PLoS One. 2016;11:e149696. Crossref

10. Sherpa ATL. Time for an organized cervical cancer screening in Bharatpur, Nepal. [dissertation]. University of Oslo, Norway; 2007.

11. Sachan PL, Singh M, Patel ML, Sachan R. A study on cervical cancer screening using pap smear test and clinical correlation. Asia Pac J Oncol Nurs 2018;5:337-41. $\underline{\text { Crossref }}$ 
12. Al Eyd GJ, Shaik RB. Rate of opportunistic pap smear screening and patterns of epithelial Cell abnormalities in pap smears in Ajman, United Arab Emirates. Sultan Qaboos Univ Med J 2012;12:473 8. Crossref

13. Bhutia K, Puri M, Gami N, Aggarwal K, Trivedi SS. Persistent inflammation on pap smear : Does it warrant evaluation? Indian J Cancer 2011;48:220 2. $\underline{\text { Crossref }}$
14. Banik U, Bhattacharjee P, Ahamad SU, Rahman Z. Pattern of epithelial cell abnormality in Pap smear: A clinicopathological and demographic correlation. Cyto Journal 2011;8:8. $\underline{\text { Crossref }}$ 